This item was submitted to Loughborough's Research Repository by the author.

Items in Figshare are protected by copyright, with all rights reserved, unless otherwise indicated.

\title{
Modelling near wall temperature gradients in "motored" spark ignition engines
}

PLEASE CITE THE PUBLISHED VERSION

PUBLISHER

(c) Society of Automotive Engineers

VERSION

VoR (Version of Record)

LICENCE

CC BY-NC-ND 4.0

\section{REPOSITORY RECORD}

Jenkin, R.J., E.H. James, and W. Malalasekera. 2019. "Modelling Near Wall Temperature Gradients in "motored" Spark Ignition Engines". figshare. https://hdl.handle.net/2134/5748. 
This item was submitted to Loughborough's Institutional Repository (https://dspace.lboro.ac.uk/) by the author and is made available under the following Creative Commons Licence conditions.

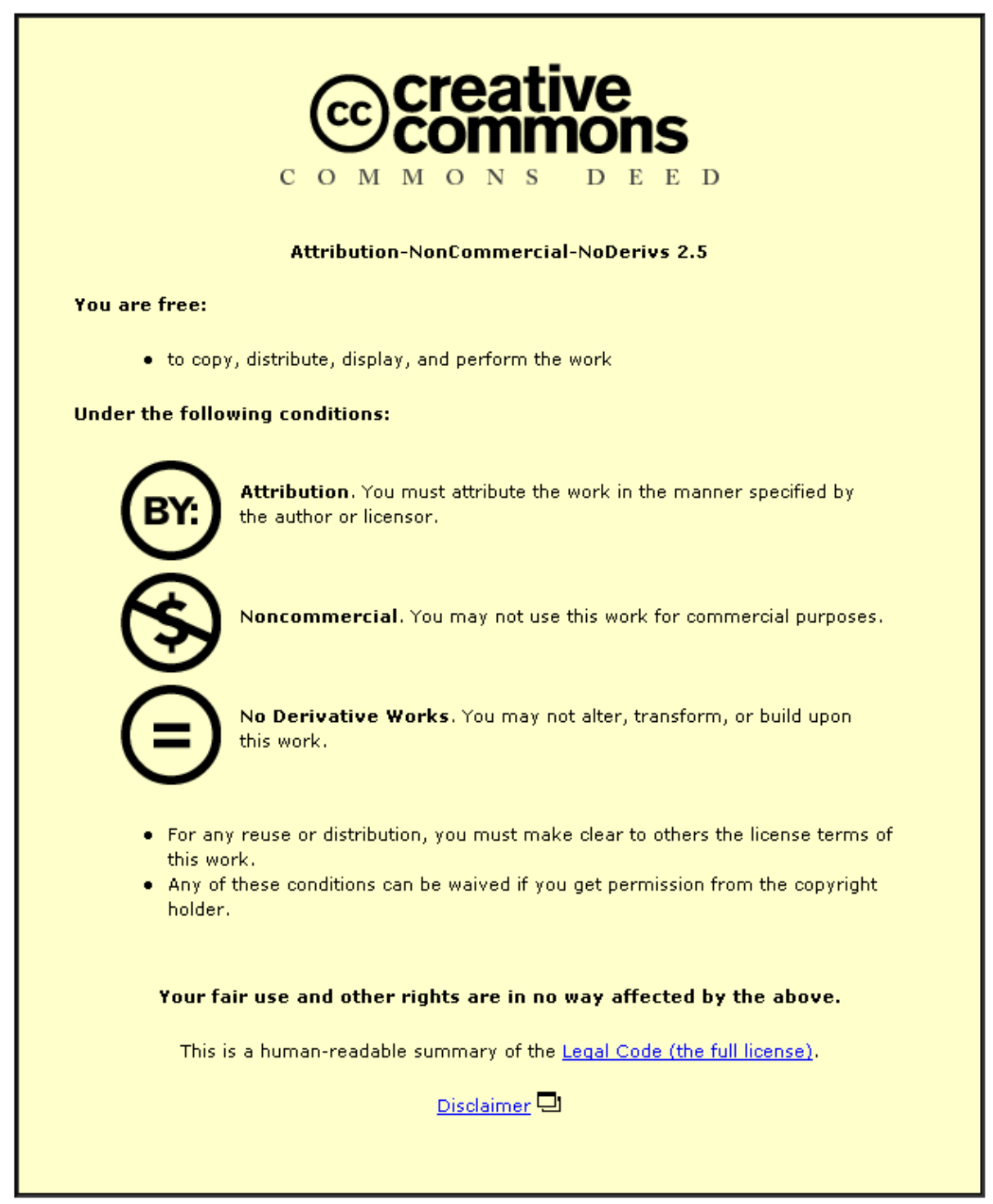

For the full text of this licence, please go to: http://creativecommons.org/licenses/by-nc-nd/2.5/ 


\title{
Modelling Near Wall Temperature Gradients in "Motored" Spark Ignition Engines
}

\author{
R. J. Jenkin, E. H. James, and W. M. Malalasekera \\ Loughborough University of Technology
}

Copyright 1996 Society of Automotive Engineers, Inc.

\section{ABSTRACT.}

A new type of model has been developed to predict near wall temperature gradients and local instantaneous heat fluxes in a "motored" engine. The unburnt charge in an existing "phenomenological" model is divided into a number of discrete masses which are assumed to be "stacked" adjacent to the cylinder surfaces. A sub-model based on the one-dimensional Enthalpy Equation is applied to the system of discrete masses in order to predict the near wall temperature distribution. Predicted temperature profiles are compared with those measured by other researchers and show good agreement under both low and high swirl conditions. Local instantaneous heat fluxes are calculated from the near wall temperature gradients, and these also show good agreement with measured results.

Near wall velocity and turbulence data have been used in modelling turbulent eddy transport processes rather than using conventional boundary layer theories. This technique has proven to be very successful in both high and low swirl situations, leading to the conclusion that conventional boundary layer theory may not be applicable to engine type flows.

\section{INTRODUCTION.}

Increasing emphasis on the reduction of engine-out pollutants and improved efficiency have created a need for more comprehensive engine simulation models to assist in the development of internal combustion engines. In particular, there is a requirement for such models to incorporate detailed information on in-cylinder temperature distributions within both the burnt and unburnt charges so that pollutant formation processes, auto-ignition etc. can be more precisely described. A main factor determining such distributions is the heat transfer to the combustion chamber surfaces.

In zero-dimensional, "phenomenological" computer models, the energy lost from the cylinder contents due to heat transfer has been catered for in various ways. These include:

i) the assumption that the effects of heat transfer are uniformly distributed throughout the bulk of the cylinder contents. In the case of two zone models (burnt and unburnt regions) or multi-zone models (where the burnt charge is divided into a number of regions [1],[2]), the effects of heat transfer between each zone and adjacent cylinder surfaces are uniformly distributed throughout the zone. Burnt and unburnt gas temperatures for the bulk of the cylinder contents can be underestimated when this method is employed.

ii) neglecting heat transfer [2]. In this instance, the temperature levels attained are at their maximum adiabatic values and are again uniform throughout each element of charge being considered.

iii) by an allowance for the development of a thermal boundary layer between the core gas and the cylinder walls [11]. A linear thermal boundary layer temperature profile is invariably assumed.

Models accounting for the thermal boundary layer are considered to be the most accurate since there is empirical evidence to show that a significant fraction of the cylinder gases are at temperatures considerably different to that of the core. Lydford-Pike and Heywood [4] used Schlieren visualisation to photograph a dark region of the order of 1 to $4 \mathrm{~mm}$ thick adjacent to the cylinder wall of a square cylinder research engine. This was attributed to the presence of a thermal boundary layer. Recently, more 
sophisticated techniques have enabled the temperature distribution adjacent to the cylinder walls to be measured. Yamada et al [5] have used speckle interferometry to measure the temperature distribution in the region between 1 and $5 \mathrm{~mm}$ from the cylinder wall over a range of operating conditions for a "motored" engine. They fitted logarithmic curves to the values acquired over several cycles to arrive at ensemble averaged near wall temperature distributions at several instants in the cycle. Lucht et al [6] used broad band coherent anti-Stokes Raman scattering (CARS) to acquire near wall temperature distributions to within 25 to $50 \mu \mathrm{m}$ of the cylinder head. Data was obtained for high and low swirl conditions in both the "motored" and fired modes of engine operation.

These investigations show that during compression, combustion and expansion considerable fractions of the cylinder gases are at temperatures significantly different to those in the adiabatic core. Lavoie and Blumberg [11] developed a "phenomenological" model which divided the cylinder contents into a bulk adiabatic core zone and a boundary layer zone. The thermal boundary layer thickness was calculated by using integral boundary layer analysis. A linear temperature distribution between the cylinder wall and adiabatic core gases was assumed. This approach has the disadvantage that integral boundary layer analysis is based on traditional incompressible boundary layer theory resulting in potentially inaccurate predicted thermal boundary layer thicknesses in the engine environment. Also, in light of the results obtained by Lucht et al [6] and Yamada et al [5], the thermal boundary layer temperature distribution is far from linear. An obvious improvement to the potential accuracy of typical in-cylinder process models is therefore to account for these near wall temperature profiles in as accurate a manner as possible rather than by simply allowing for linear temperature gradients at all times.

Multi-dimensional engine cycle modelling is the obvious approach one could use to achieve this. However there are several difficulties when modelling the thermal boundary layer using this method. Firstly, the thermal boundary layer is very thin in comparison to the overall domain size. With the mesh sizes necessary to maintain reasonable computational times, the first node adjacent to the wall is generally outside the thermal boundary layer. Secondly, separate sets of $k-\varepsilon$ equations have to be formulated for the boundary layer and bulk gases due to considerable differences in the governing physics. Jennings and Morel [7] have overcome these problems by using a separate fine grid adjacent to the cylinder wall. Different formulations of the $k-\varepsilon$ equations are used for the boundary layer and bulk flow regions to account for the physical differences in their flow characteristics. They have resolved the near-wall in-cylinder gas temperature distribution, but have not compared their results with measured values. More frequently, wall function methods are used to calculate the cylinder wall heat flux and the temperature of the nodes adjacent to the cylinder wall. This type of approach uses conventional flat plate boundary layer theory or onedimensional conduction [10] to develop expressions for an assumed temperature profile between the cylinder wall and the nodes immediately adjacent to it enabling the estimation of gas/wall interface heat flux and the near wall nodal temperatures.

In the study to be outlined here, in order to overcome the computational time limitations that hinder the development of multi-dimensional engine simulations and the lack of near wall temperature information provided by thermodynamic models, a new type of model has been developed. Essentially, this is of the "phenomenological" type but with the application of a finite volume type formulation of the Conservation of Enthalpy Equation for the regions adjacent to the cylinder wall. The model, at its present stage of development, simulates the compression and expansion strokes for a "motored" engine cycle only. This paper describes the model and compares relevant calculated temperature distribution results with those measured by Lucht et al [6].

\section{PREVIOUS WORK.}

Engine heat transfer studies have traditionally resulted in expressions predicting the heat flux between the bulk gas and the cylinder walls. Much of this work is relevant to modelling near wall temperature distributions as many such studies have been based on boundary layer theory. The most commonly applied theories of this type make the fundamental assumption that in-cylinder heat transfer processes are quasi-steady and can be approximated by heat transfer in fully developed, turbulent pipe flows for which much experimental data is available. In this respect, Annand [12] reviewed the literature and developed an expression for instantaneous global heat flux using a Reynolds Number based on the mean piston speed. This approach is still popular and is commonly used in zerodimensional "phenomenological" models. Its main attraction is its simplicity and, with the correct empirical input, acceptable accuracy for many applications. Annand [12] noted however that measured instantaneous heat fluxes were out of phase with the heat transfer driving temperature difference. A modified equation to account for non-steady effects based on the rate of change of gas temperature was then proposed [13].

Until quite recently, non-steady effects have generally been ignored. As engine cycle modelling requirements have increased however, the lag between heat flux and driving temperature difference as a result of non-steady effects has undergone more thorough investigation. Lawton [14] used the Conservation of Energy Equation in the form;

$$
\frac{\partial T}{\partial t}=\alpha \frac{d^{2} T}{d x^{2}}-\frac{n-1}{V} \frac{d V}{d t} T=0
$$

to determine the influence of compression and expansion on heat transfer. The work source term in the case of a "motored" engine in the absence of viscous heating is 


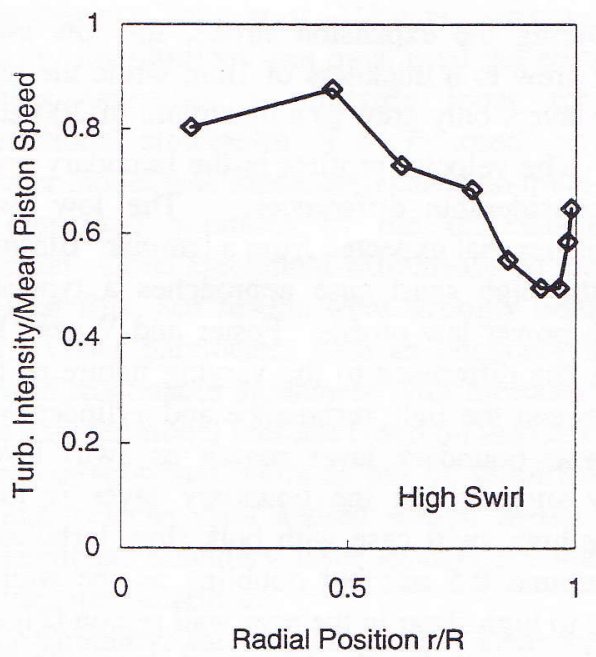

Figure 1. Tangential Turbulence Intensities with Radial Position at TDC -"Motored" Conditions. (From Hall \& Bracco [18].)

entirely attributable to compression and expansion effects. Lawton [14] solved EQ (1) in finite difference form using a fully explicit method to produce simulated boundary layer temperature profiles. He subsequently used Fourier's Law

$$
q=-k \frac{d T}{d x}
$$

to evaluate the gas-wall interface heat fluxes from these profiles. The calculated heat fluxes showed good agreement with measured results. Lawton further produced a correction factor to account for non-steady effects in quasisteady heat transfer correlations.

Jennings and Morel [15] have performed several case studies in an attempt to assess the applicability of conventional boundary layer theories to engine type flows and their relevance to multi-dimensional modelling of such flows. They considered the effects of turbulence, separating/reattaching flows, flow unsteadiness and combustion. Their results amplify concerns that turbulent transport within engine type flows varies significantly from that predicted by constant pressure boundary layer theory.

Attempts have been made to derive more accurate heat transfer models using complex boundary layer theories for application in both zero and multi-dimensional models ([8],[9],[10],[16],[17]). Reitz [8] and Huh et al [9] assessed the applicability of the Law of the Wall type approach to boundary layer approximation in multi-dimensional codes. Reitz [8] concluded that different implementations of the wall function methods lead to different heat flux predictions whereas Huh et al [9] found that traditional wall function methods for heat transfer predictions can result in significant under predictions in some cases. Both Reitz [8] and Huh et al [9] note that the pressure work term has a significant effect on the net predicted heat transfer rate. Yang and Martin [10] developed the one-dimensional energy equation to provide an alternative method for calculating heat flux. This approach was compared with the Law of the Wall type methods by Huh et al [9] who were unable to conclusively determine which method is superior. Puzinauskas and Borgnakke [16] derived a mixing length using an underlying lumped zone $k-\varepsilon$ turbulence model to account for the turbulent convection of heat. Their model accurately predicts peak heat flux as well as the effects of the work source term. Chen and Veshag [17] have developed a model derived from the solutions of the full, one-dimensional equations of the transient, compressible boundary layer, but have based their assumed velocity and temperature profiles on steady state equivalents. Their predicted results are nevertheless in good agreement with measurements.

Thus, many studies have attempted to improve on the accuracy with which engine cylinder wall heat fluxes can be predicted. Several of these have provided alternative techniques for modelling in-cylinder heat transfer processes. Instead of using the fully developed turbulent pipe flow analogy, models simulating the effects of real in-cylinder near wall flows have been developed generally based on flat plate turbulent boundary layer theory and turbulence models of varying complexity. No single model has proved superior, and there is continuing speculation as to the applicability of conventional boundary layer modelling techniques in the simulation of engine heat transfer processes. There is also clear evidence that local incylinder gas motion and the rate of pressure change significantly influence engine heat transfer and thermal boundary layer temperature distributions.

In-cylinder charge motion in particular has a significant influence on local heat flux. Of special interest when modelling in-cylinder boundary layers are the flow

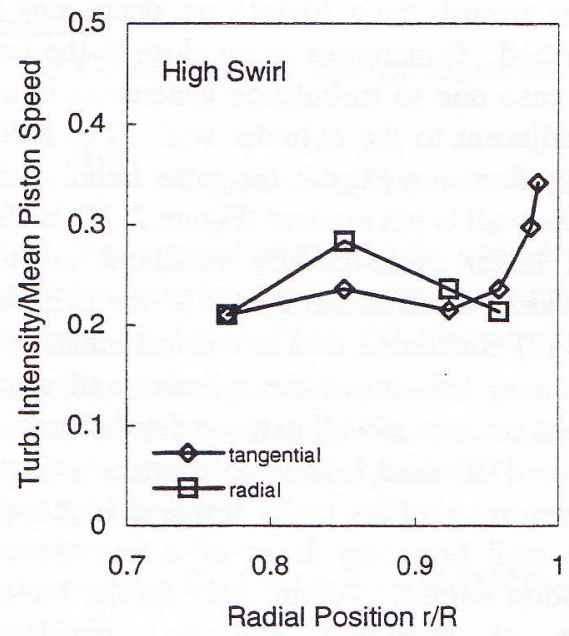

Figure 2. Tangential and Radial Turbulence Intensities with Radial Position at $20^{\circ}$ ATDC -"Motored" Condition. (From Hall \& Bracco [18].) 


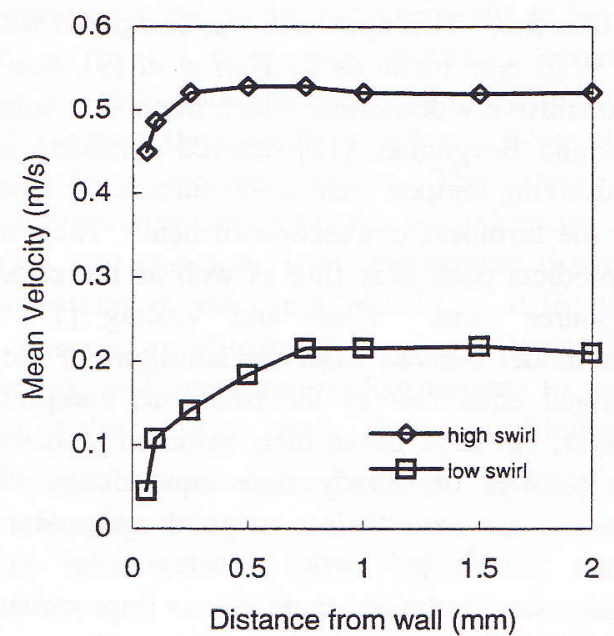

Figure 3. Measured Boundary Layer Velocity Distributions for High and Low Swirl Cases Shortly After TDC. in Non-Firing Cycles (From Foster \& Witze [19])

characteristics near to and within the momentum boundary layer. The turbulence and velocity characteristics of near wall in-cylinder flows have been measured by several researchers [18][19][20][21]. Hall and Bracco [18] used Laser Doppler Velocimetry (L.D.V.) to make cycle resolved velocity and turbulence measurements in a spark ignition engine. Both tangential (parallel to cylinder wall) and radial (normal to cylinder wall) components of mean velocity and turbulence intensity were measured under "motored" and fired modes of engine operation. Only the results obtained in the "motored" mode of engine operation will be discussed here. The turbulence intensity in the tangential direction is shown in Figure 1. Turbulence intensity is greatest towards the cylinder core, decreasing as the wall is approached. It increases again close to the wall in the high swirl case due to turbulence generation in the high shear layer adjacent to the cylinder wall. The radial turbulence intensity does not exhibit the same trend as the increase close to the wall is not evident (Figure 2). It is also worth noting that larger cycle-to-cycle variations in bulk velocities were evident towards the centre of the cylinder. Hall and Bracco [18] concluded that turbulence intensity is isotropic except within $1.5 \mathrm{~mm}$ of the cylinder wall where there is a significant amount of wall generated turbulence.

Foster and Witze [19] used L.D.V. to measure velocity and turbulence intensity profiles under low and high swirl conditions in the wall boundary layer of a homogenous charge spark ignition engine. Again, only results for the "motored" mode of operation will be considered. Considerable differences were noted between the high and low swirl velocity profiles. Higher levels of swirl impeded the development of the velocity boundary layer with thicknesses of less than $70 \mu \mathrm{m}$ being observed during compression compared with 200 to $300 \mu \mathrm{m}$ for the low swirl case. During the expansion stroke, the low swirl boundary layer grew to a thickness of $1 \mathrm{~mm}$ while the high swirl boundary layers only grew to a maximum of $200 \mu \mathrm{m}$ (see Figure 3). The velocity profiles in the boundary layer also showed considerable differences. The low swirl profile approximates that expected from a laminar "Blasius" profile while the high swirl case approaches a typically turbulent $1 / 7$ th power law profile. Foster and Witze [19] have attributed this difference to the varying nature of the interactions between the bulk turbulence and cylinder wall in the high shear boundary layer region as swirl levels change. They suggest that the boundary layer is fully turbulent in the high swirl case with bulk flow turbulence intensities of around $0.5 \mathrm{~m} / \mathrm{s}$ but doubling as the wall is approached due to high shear in the near wall region (Figure 4). In marked contrast, for the low swirl case, the free stream turbulence intensity is of the order of $0.3 \mathrm{~m} / \mathrm{s}$ under the engine conditions used reducing as the wall is approached. Foster and Witze conclude that in the low swirl case, boundary layer growth is due to entrainment at the outer layer rather than wall generated vorticity. This helps to explain why the low swirl mean velocity profile demonstrates laminar characteristics close to the wall.

Pierce et al [20] used L.D.V. to make velocity measurements near the cylinder head of a four stroke engine. Their studies show that the behaviour of the fluid near the wall depends on engine intake geometry, combustion chamber geometry and operating conditions. They also question whether conventional momentum boundary layers exist in engine cylinders because of fluid rotation, wall scrubbing and, most importantly, the relative thinness of measured boundary layers compared with

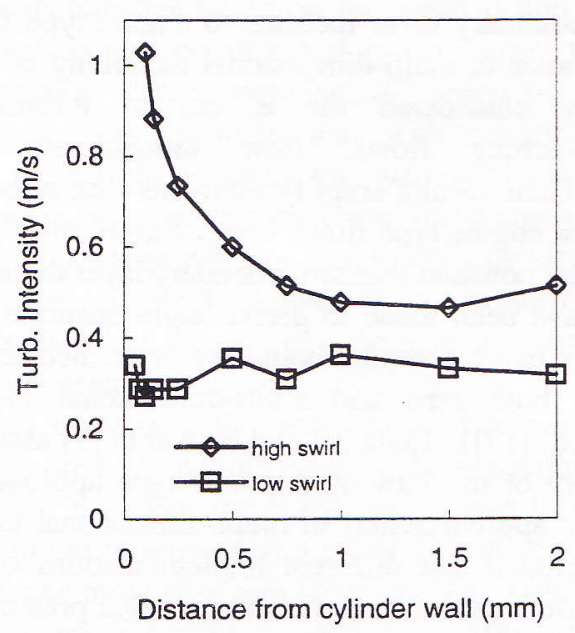

Figure 4. Comparison of Measured Boundary Layer Turbulence Intensity Distributions for High and Low Swirl Cases Shortly After TDC in Non-Firing Cycles. (From Foster \& Witze [19].) 
thicknesses calculated using flat plate turbulent boundary layer theory. Yang et al [21] have measured the near wall velocity distributions and have used the ensuing calculated friction velocities to provide input for their multidimensional simulation of a "motored" engine. A heat transfer model was formulated based on multi-parameter fits to numerical solutions of the one-dimensional energy equation. Good agreement with measured results was found for heat flux, but results were strongly dependant on grid size. Other parameters such as boundary layer thickness showed reasonable agreement with measured values. This heat transfer model was not based on the Law of the Wall or other conventional methods but on empirical velocity and friction velocity data adding weight to the argument that conventional boundary layer models are not applicable in engine type situations.

In summary, there is conclusive evidence to verify the existence of an area of low momentum fluid adjacent to the cylinder walls of typical internal combustion engines. The mechanisms for transfer of momentum within these layers are complex and open to speculation. However, there is good evidence to suggest that conventional, fully developed turbulent boundary layer theory is not applicable to engine type flows primarily due to the high turbulence intensities [19] in the "free stream" core bulk flow [20]. There is also strong evidence to support the theory that near wall turbulence characteristics have a strong influence on the turbulent transport of heat within the cylinders of internal combustion engines and, subsequently, have a strong influence on local instantaneous heat flux and thermal boundary layer temperature distributions.

\section{THEORETICAL.}

Development of the thermal boundary layer is strongly coupled with in-cylinder fluid motions, especially those close to the cylinder wall. A knowledge of the near wall turbulence and mean flow distribution is thus required before its effects on heat transfer and thermal boundary

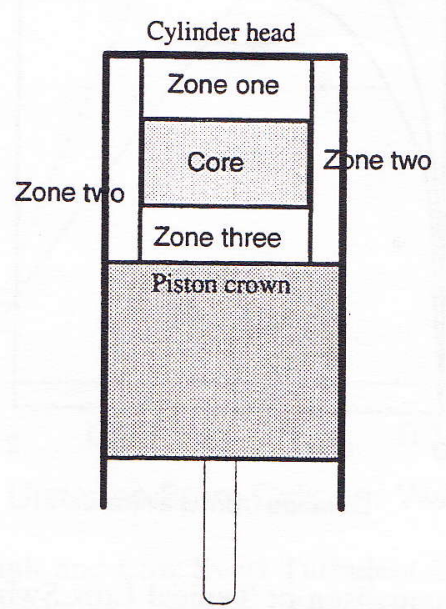

Figure 5. Cylinder Contents Zone Layout.

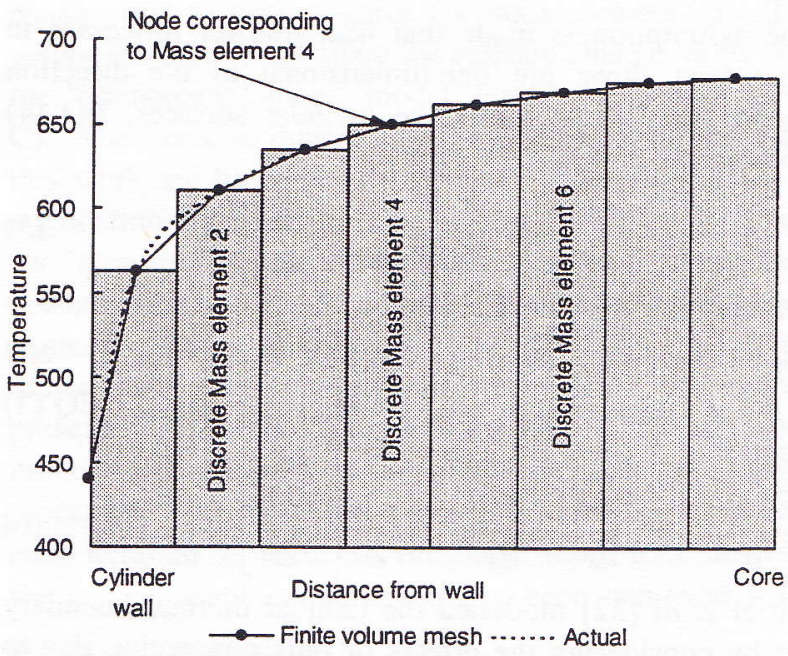

Figure 6. Diagrammatic Representation of the Superposition of the System of Discrete Masses and the Finite Volume Mesh.

layer development can be accounted for. As presented in the literature survey, many techniques have been used to model near wall turbulence structure and velocity distribution and its subsequent effects on the thermal boundary layer temperature distribution. Most techniques are based on traditional boundary layer models, but there is much speculation as to the applicability of such approaches when modelling in-cylinder near wall turbulence structure and mean flow velocity distribution.

In this work, a thermal boundary layer model is developed from the Conservation of Energy equation. This technique has been used many times before [10][17][22] but, in this application, a more fundamental approach to modelling the contribution of turbulent transport processes to the overall energy balance is employed, based on empirical near wall turbulence data taken from the literature.

The Conservation of Energy Equation can be expressed as:

$$
\frac{\partial(\rho i)}{\partial t}+\nabla \cdot(\rho i \mathbf{u})=-P \nabla \cdot \mathbf{u}+\Phi+\nabla \cdot(k \nabla T)+S_{i}
$$

where the internal energy $i$ is considered as the only significant energy storage term. Enthalpy $h$ can be expressed by $h=i+\mathrm{P} / \mathrm{\rho}$. If $i$ is substituted by $h-\mathrm{P} / \mathrm{\rho}$ in EQ (3), after considerable re-arrangement we can express the Conservation of Energy Equation in terms of enthalpy $h$. In the absence of pressure gradients and viscous heating, EQ (3) becomes:

$$
\frac{\partial(\rho h)}{\partial t}+\nabla \cdot(h \rho \mathbf{u})=\frac{d \mathrm{P}}{d t}+\nabla \cdot(k \nabla \mathrm{T})+\mathrm{S}_{h}
$$

EQ (4) is the Conservation of Enthalpy Equation for a compressible system.

By considering enthalpy as the conserved property, the pressure work is expressed in terms of the time derivative of pressure, making the dominant work term non-dimensional. 
If the assumption is made that heat transfer processes in engine type flows are one-dimensional in the direction perpendicular to the respective cylinder surfaces, EQ (4) becomes:

$$
\frac{\partial(\rho h)}{\partial t}+\frac{\partial(\rho h u)}{\partial x}=\frac{\partial}{\partial x}\left(k \frac{\partial T}{\partial x}\right)+\frac{d P}{d t}+S_{h}
$$

Making the further assumption that for a particle, $k$ is constant and expressing $\rho h$ and $u$ as $\rho h=\overline{\rho h}+\gamma$ and $u=\bar{u}+u^{\prime}$, after rearrangement and averaging [23], EQ (5) becomes:

$$
\frac{\partial \overline{(\rho h)}}{\partial t}+\bar{u} \frac{\partial \overline{(\rho h)}}{\partial x}+\frac{\partial}{\partial x} \overline{u^{\prime} \gamma}=\frac{\partial}{\partial x}\left[k \frac{\partial \bar{T}}{\partial x}\right]+\frac{d P}{d t}+S_{h}
$$

Grief et al [22] modelled the laminar thermal boundary layer by considering the effects of bulk convection due to gas density changes. During compression, there is an insignificant difference in laminar thermal boundary layer development when the convective effects of density change are accounted for. Inclusion of the convective term during expansion results in a reduction of thermal boundary layer thickness compared with a continuing growth when the convective term is omitted. This error is reduced in our analysis as the diffusion term, with the inclusion of turbulent transport effects, dominates the bulk convective term. Experimental evidence presented by Pierce et al [20] shows that mean fluid motion normal to the cylinder wall is very small, reducing bulk flow convective effects to insignificance for the purposes of this study. This justifies the omission of the bulk convective term, $\bar{u} \partial \overline{(\rho h)} / \partial x$, in EQ (6), which then becomes:

$$
\frac{\partial \overline{(\rho h)}}{\partial t}=\frac{\partial}{\partial x}\left[k \frac{\partial \bar{T}}{\partial x}-\overline{u^{\prime} \gamma}\right]+\frac{d P}{d t}+S_{h}
$$

In order to simplify the term accounting for turbulent convective motion, an eddy transport coefficient or "turbulent thermal conductivity", $k_{t}$, is introduced just as Boussinesq (see Hinze[23]) did for the transport of momentum. In one dimension, this can be expressed as:

$$
-\overline{\gamma u^{\prime}}=k_{t} \frac{\partial \bar{T}}{\partial x}
$$

with $k_{t}$ being a scalar quantity. EQ (6) is finally expressed as:

$$
\frac{\partial \overline{(\rho h)}}{\partial t}=\frac{\partial}{\partial x}\left[\left(k+k_{t}\right) \frac{\partial \bar{T}}{\partial x}\right]+\frac{d P}{d t}+S_{h}
$$

EQ (8) is discretized by integrating over a finite volume and time, using a central differencing scheme to express the diffusion term (Patankar [24]). A full description of the method is included in Appendix A.

The above concepts were applied to an existing zerodimensional model under 'motored' engine conditions. The unburnt charge domain was split into four separate zones (see Figure 5) three of which are adjacent to the combustion chamber surfaces. These are: i. the cylinder head zone

ii. the cylinder wall zone

iii. the piston crown zone.

The fourth zone (iv.) is the central adiabatic core. Zones i. to iii. are divided into a number of discreet mass elements (usually between 20 and 150) perpendicular to the relevant combustion chamber surface. These are assumed to remain in stacked layers adjacent to their respective surfaces. As pressures and temperatures change, the densities of the discrete masses increase or decrease thereby affecting their volumes.

Lydford-Pike \& Heywood [4] showed that isotherms are predominantly parallel to the cylinder wall with slight distortions at the piston/cylinder wall and cylinder head/cylinder wall intersections. Two dimensional effects at the piston/cylinder wall and cylinder head/wall interfaces have not been modelled here. One dimensional conduction is assumed to prevail over a majority of the cylinder surfaces reducing the two-dimensional corner effects to insignificance. More complex geometric layouts, accounting more accurately for two-dimensional corner effects, were tested with no appreciable improvement in results.

The discrete masses used by the "phenomenological" model can be "dimensionalised" at any instant by considering their specific volume and the geometry of the cylinder surface against which they are "stacked". At any instant, once the current geometry of a mass element is established, the geometric centre of each mass can be represented by a node which is at the temperature of the discrete mass (the "phenomenological" model assumes that

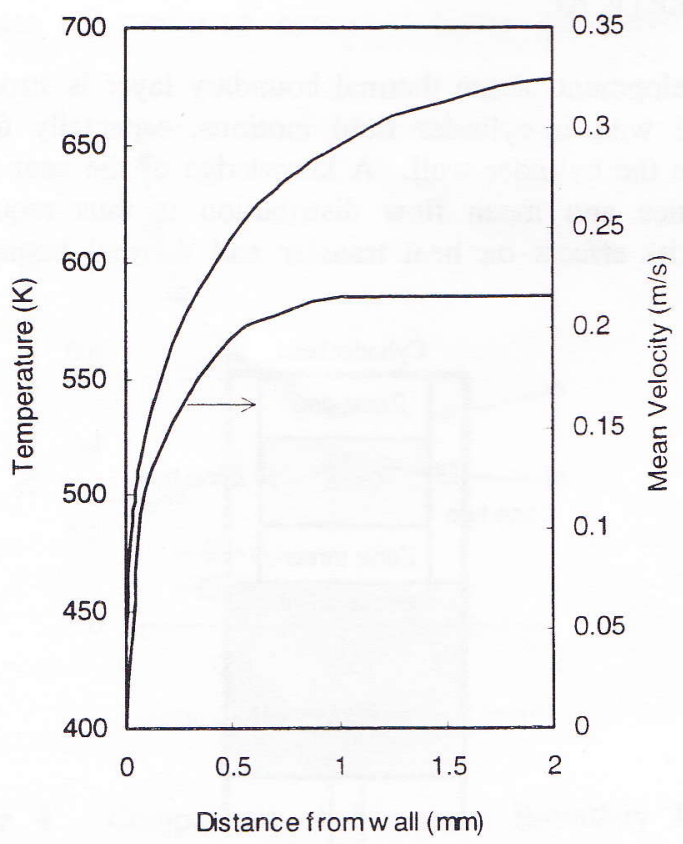

Figure 7. Comparison of Typical Low Swirl Thermal and Velocity Boundary Layers ([6][19]). 
all properties are constant throughout the respective masses). These are called the "mass nodal positions". These assumptions allow us to represent, for any instant in time, the system of zero-dimensional discrete masses with a set of spatially resolved control volumes whose average properties are equal to the properties of their corresponding discrete masses. Equations (A3) or (A4) (Appendix A) can then be directly applied to these. Figure 6 shows this schematically

The application of the one-dimensional Enthalpy Equation control volume grid to the spatially resolved discrete masses is achieved by making the assumption that, for a small increment in time, mass nodal positions change very little. Discrete masses are approximately represented by corresponding finite volumes with fixed nodal positions equivalent to the average mass "nodal positions" for the small time interval of interest.

The solution proceeds as follows. Firstly, for a particular time interval (period of crank angle rotation), the fully implicit, discretized, one-dimensional Enthalpy Equation (EQ A3 or A4) is applied to the control volume nodal grid representing the system of discrete masses (Figure 6) and is solved directly. This gives the first guess (within the iterative solution technique) temperatures for each discrete mass at the end of the time interval. From this, the energy loss due to heat transfer from each discrete mass can be calculated using the following equation (Appendix B contains a full derivation):

$$
\begin{aligned}
q_{\text {mass }, j} & \approx\left[\bar{C}_{p}\left(T_{p}-T_{p O}\right)\right]_{C V_{i, j}} \\
& -\left(\mathrm{P}-\mathrm{P}_{O}\right) \bar{v}_{C V_{i, j}}-\mathrm{S}_{h} \Delta t \bar{v}_{C V_{i, j}}
\end{aligned}
$$

The calculated values of $q_{\text {mass }_{i, j}}$ give the specific energy

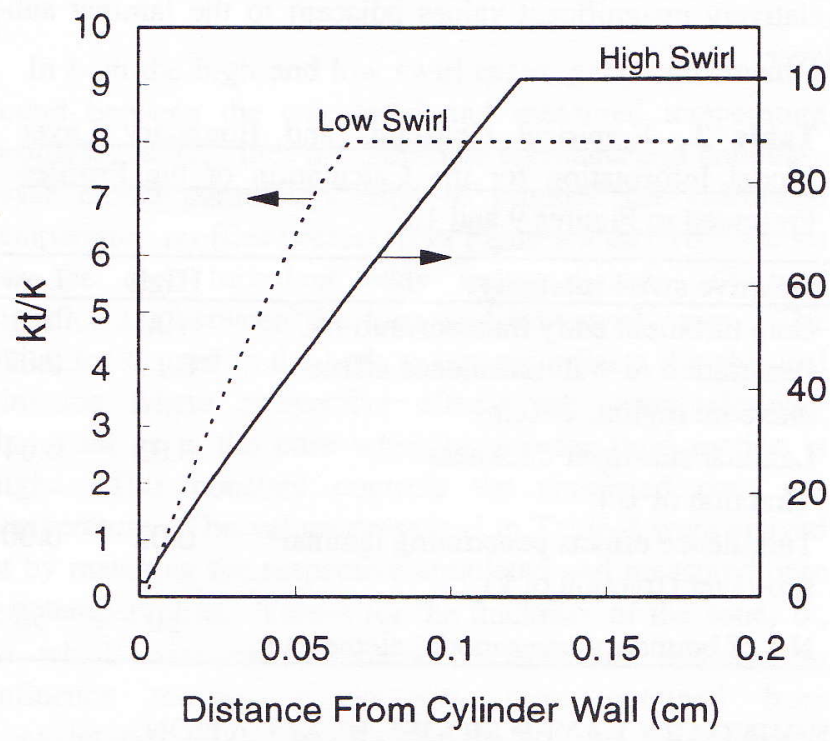

Figure 8. High and Low Swirl Turbulent Eddy : Laminar Thermal Conductivity Ratios for the Calculation of Temperature Profiles in Figures 9 and 10. change due to heat transfer for mass element $i, j$. These values are used to calculate the entropy change terms within the "phenomenological" model iterative matrix (Appendix C). The iterative mathematical modelling routines used in this work are based on those used by James [2]. In this application however, they have been modified to account for "motored" engine operation with unburnt charge alone present in the combustion chamber. A set of simultaneous equations ensues to account for all the individual discreet masses as well as the adiabatic core. These equations are presented in matrix form in Appendix $\mathrm{C}$ and are solved iteratively until balance is achieved to some stipulated precision. The boundary-layer sub-model is invoked for each iteration so as to provide new, more accurate values for $q_{\text {mass }}$ until convergence has been achieved for the respective time step.

Each iteration evaluates a new thermal boundary layer temperature distribution using the one-dimensional Enthalpy Equation sub-model and the intermediate (iterative) values of pressure for the work source term calculations. Essentially, the discretized one-dimensional Enthalpy Equation sub-model provides heat transfer and temperature distribution information for the modified "phenomenological" model.

Eddy and laminar thermal conductivities have a strong influence on the development of the thermal boundary layer. Laminar thermal conductivity is considered to be proportional to the absolute fluid temperature according to the equation;

$$
k=k_{0}\left(\frac{T}{T_{0}}\right)
$$

Turbulent thermal conductivity, as well as being a function of the laminar thermal conductivity, is dependent on the fluid turbulent eddy motion. It is considered to be proportional to its laminar counterpart according to the equation:

$$
k_{r}=C k
$$

with constant, $C$, accounting for turbulent eddy transport processes. $C$ is a function of time and space.

A "phenomenological" approach is used to determine instantaneous local values of $C$ from consideration of measured near wall turbulence intensity and bulk velocity distributions ([18],[19],[20]). Fundamentally, the thermal boundary layer is divided into three zones not dissimilar to the methods employed in classical boundary layer theory. Adjacent to the wall, a laminar sub-layer approximately $0.02 \delta$ thick (where $\delta$ is the thickness of the region affected by near wall turbulence) is assumed to exist (see Figure 8). Figure 7 sketches typical thermal and velocity boundary layer distributions. It is immediately apparent that the regions of the thermal boundary layer away from the wall are outside the influence of the velocity boundary layer. In this region, turbulent eddy transport processes are assumed to be spatially uniform based on the observation that core turbulence is isotropic [18]. Between the outer 
If the assumption is made that heat transfer processes in engine type flows are one-dimensional in the direction perpendicular to the respective cylinder surfaces, EQ (4) becomes:

$$
\frac{\partial(\rho h)}{\partial t}+\frac{\partial(\rho h u)}{\partial x}=\frac{\partial}{\partial x}\left(k \frac{\partial T}{\partial x}\right)+\frac{d P}{d t}+S_{h}
$$

Making the further assumption that for a particle, $k$ is constant and expressing $\rho h$ and $u$ as $\rho h=\overline{\rho h}+\gamma$ and $u=\bar{u}+u^{\prime}$, after rearrangement and averaging [23], EQ (5) becomes:

$$
\frac{\partial \overline{(\rho h)}}{\partial t}+\bar{u} \frac{\partial \overline{(\rho h)}}{\partial x}+\frac{\partial}{\partial x} \overline{u^{\prime} \gamma}=\frac{\partial}{\partial x}\left[k \frac{\partial \bar{T}}{\partial x}\right]+\frac{d P}{d t}+S_{h}
$$

Grief et al [22] modelled the laminar thermal boundary layer by considering the effects of bulk convection due to gas density changes. During compression, there is an insignificant difference in laminar thermal boundary layer development when the convective effects of density change are accounted for. Inclusion of the convective term during expansion results in a reduction of thermal boundary layer thickness compared with a continuing growth when the convective term is omitted. This error is reduced in our analysis as the diffusion term, with the inclusion of turbulent transport effects, dominates the bulk convective term. Experimental evidence presented by Pierce et al [20] shows that mean fluid motion normal to the cylinder wall is very small, reducing bulk flow convective effects to insignificance for the purposes of this study. This justifies the omission of the bulk convective term, $\bar{u} \partial \overline{(\rho h)} / \partial x$, in $\mathrm{EQ}(6)$, which then becomes:

$$
\frac{\partial \overline{(\rho h)}}{\partial t}=\frac{\partial}{\partial x}\left[k \frac{\partial \bar{T}}{\partial x}-\overline{u^{\prime} \gamma}\right]+\frac{d P}{d t}+S_{h}
$$

In order to simplify the term accounting for turbulent convective motion, an eddy transport coefficient or "turbulent thermal conductivity", $k_{t}$, is introduced just as Boussinesq (see Hinze[23]) did for the transport of momentum. In one dimension, this can be expressed as:

$$
-\overline{\gamma u^{\prime}}=k_{t} \frac{\partial \bar{T}}{\partial x}
$$

with $k_{t}$ being a scalar quantity. EQ (6) is finally expressed as:

$$
\frac{\partial \overline{(\rho h)}}{\partial t}=\frac{\partial}{\partial x}\left[\left(k+k_{t}\right) \frac{\partial \bar{T}}{\partial x}\right]+\frac{d P}{d t}+S_{h}
$$

EQ (8) is discretized by integrating over a finite volume and time, using a central differencing scheme to express the diffusion term (Patankar [24]). A full description of the method is included in Appendix A.

The above concepts were applied to an existing zerodimensional model under 'motored' engine conditions. The unburnt charge domain was split into four separate zones (see Figure 5) three of which are adjacent to the combustion chamber surfaces. These are: i. the cylinder head zone

ii. the cylinder wall zone

iii. the piston crown zone.

The fourth zone (iv.) is the central adiabatic core. Zones i. to iii. are divided into a number of discreet mass elements (usually between 20 and 150) perpendicular to the relevant combustion chamber surface. These are assumed to remain in stacked layers adjacent to their respective surfaces. As pressures and temperatures change, the densities of the discrete masses increase or decrease thereby affecting their volumes.

Lydford-Pike \& Heywood [4] showed that isotherms are predominantly parallel to the cylinder wall with slight distortions at the piston/cylinder wall and cylinder head/cylinder wall intersections. Two dimensional effects at the piston/cylinder wall and cylinder head/wall interfaces have not been modelled here. One dimensional conduction is assumed to prevail over a majority of the cylinder surfaces reducing the two-dimensional corner effects to insignificance. More complex geometric layouts, accounting more accurately for two-dimensional corner effects, were tested with no appreciable improvement in results.

The discrete masses used by the "phenomenological" model can be "dimensionalised" at any instant by considering their specific volume and the geometry of the cylinder surface against which they are "stacked". At any instant, once the current geometry of a mass element is established, the geometric centre of each mass can be represented by a node which is at the temperature of the discrete mass (the "phenomenological" model assumes that

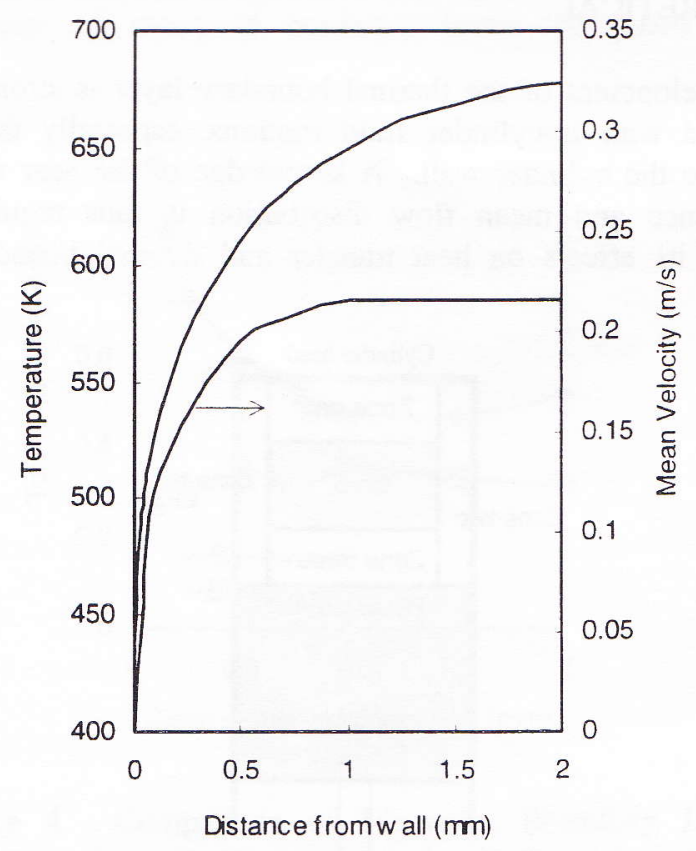

Figure 7. Comparison of Typical Low Swirl Thermal and Velocity Boundary Layers ([6][19]). 
"constant" eddy conductivity region and the near wall laminar region is a transition region roughly corresponding to the overlap of the velocity and thermal boundary layers. Velocity and turbulence structures and their subsequent effect on the transport of heat in this region are complex and have been the subject of many of the studies discussed earlier. In this region, none of the classical approaches have proven to be completely successful. At the near wall edge of the transition region, adjacent to the laminar sub-layer, turbulent eddy transport processes are assumed to be negligible and, at the outer edge of the transition region, turbulent thermal conductivity is assumed to have a value dependent on the bulk charge turbulence intensity.

Near wall turbulence is anisotropic (Hall \& Bracco [18]). It is assumed that, in the case of one-dimensional heat transfer, only the component of eddy-velocity normal to the relevant combustion chamber surface will contribute to the eddy transport of heat from the charge to the surface. Figure 2 compares radial and tangential turbulence intensities measured in the cylinder of an engine. The radial turbulence intensity (normal to the cylinder wall) does not exhibit the near wall peak observed in the tangential turbulence intensity profile. Schlichting [25] plots near wall turbulence intensities for fully developed turbulent pipe flow. His results show an approximately linear increase in normal turbulence intensity from a minimum adjacent to the pipe wall to a maximum value towards the outer limits of the velocity boundary layer. Even though the results presented in [25] are for steady pipe flow, similarities exist between these results and those obtained by Hall \& Bracco [18] in the cylinder of an internal combustion engine. In the

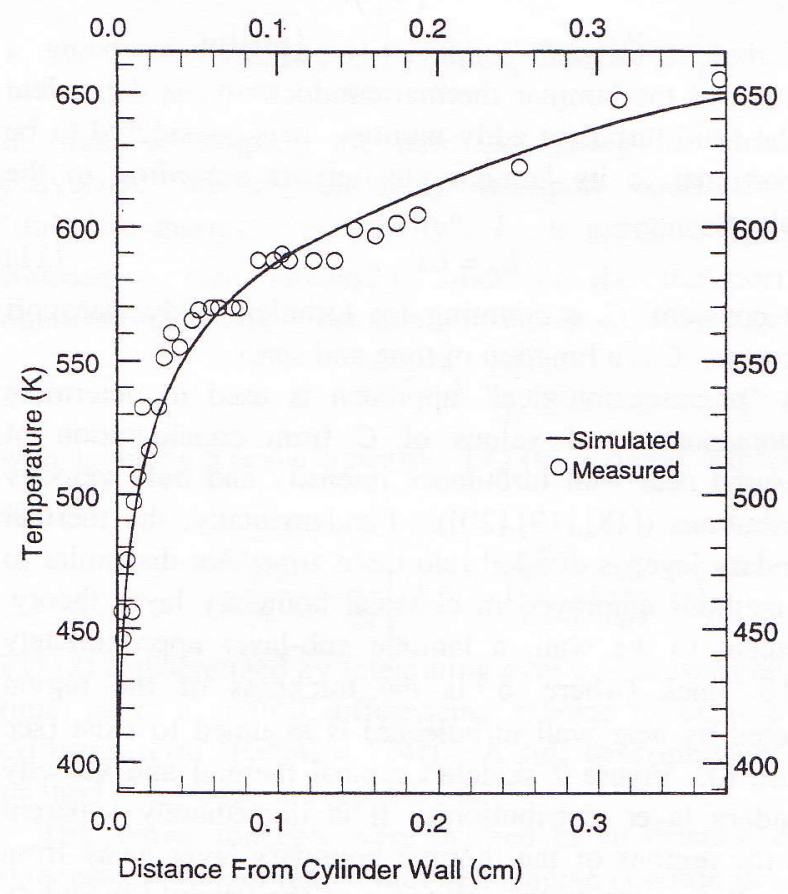

Figure 9. High Swirl Measured TDC Thermal Boundary Layer Profile (Lucht et al [6]) Compared with Calculated Profile.
Table 1. Engine Operating Conditions (Lucht et al [6])

$\begin{array}{ll}\text { Compression ratio } & 7.0 \\ \text { Engine speed (r.p.m.) } & 600 \\ \text { Intake air temperature (K) } & 373 \\ \text { Intake air pressure (atm) } & 1.27\end{array}$

absence of actual in-cylinder measurements extremely close to the wall, it is not unreasonable to assume, in light of Schlichting's work, that the normal turbulence intensity distribution approaches a straight line.

For the purposes of the work presented in this paper, it has proven to be acceptable to use the assumption that $k_{t} / k$ (ie. $C$ in $\mathrm{EQ}(11)$ ), is approximately proportional to the turbulence intensity. Figure 8 plots typical high and low swirl distributions for $C$. The laminar sub-layer and the inner edge of the transition region are easily determinable in the high swirl case. Initially, the model was developed to allow for time dependent variation of turbulence effects. However, the introduction of an unvarying $k_{t} / k$ spatial distribution had little effect on the simulated thermal boundary layer temperature profiles and the calculated heat fluxes.

In summary, a "phenomenological" type model has been developed to account for the effects of the turbulent eddy transport of enthalpy in internal combustion engine near wall in-cylinder flows. An empirical constant, $\delta$, accounting for the penetration of near-wall turbulence effects into the bulk charge, is derived from near wall turbulence and velocity data. This marks the boundary between the core (where turbulence is assumed to be isotropic and turbulent effects are considered to be uniform in both time and space) and the transition region. Here, turbulence and its subsequent effect on the ratio of $k_{t} / k$ is assumed to decrease linearly from the constant core value to relatively insignificant values adjacent to the laminar sublayer.

Table 2. Empirical Constants and Boundary Layer Model Information for the Calculation of the Profiles Presented in Figures 9 and 10.

\begin{tabular}{lcc}
\hline Relative swirl intensity: & High & Low \\
\hline $\begin{array}{l}\text { Core turbulent eddy transport ratio, } C \\
\text { Penetration of wall turbulence effects } \\
\text { into core region, } \delta(\mathrm{cm})\end{array}$ & 0.13 & 0.07 \\
$\begin{array}{l}\text { Laminar sub-layer thickness } \\
\text { (fraction of } \delta \text { ) }\end{array}$ & 0.02 & 0.04 \\
$\begin{array}{l}\text { Turbulence effects penetrating laminar } \\
\text { sub-layer (fraction of k) }\end{array}$ & 0.02 & 0.00 \\
\begin{tabular}{l} 
No. of boundary layer model elements. \\
\hline
\end{tabular} & 50 & 50 \\
\hline
\end{tabular}

\section{BOUNDARY LAYER MODEL EVALUATION.}

Lucht et al [6] have obtained thermal boundary layer temperature distributions using the C.A.R.S. technique in 


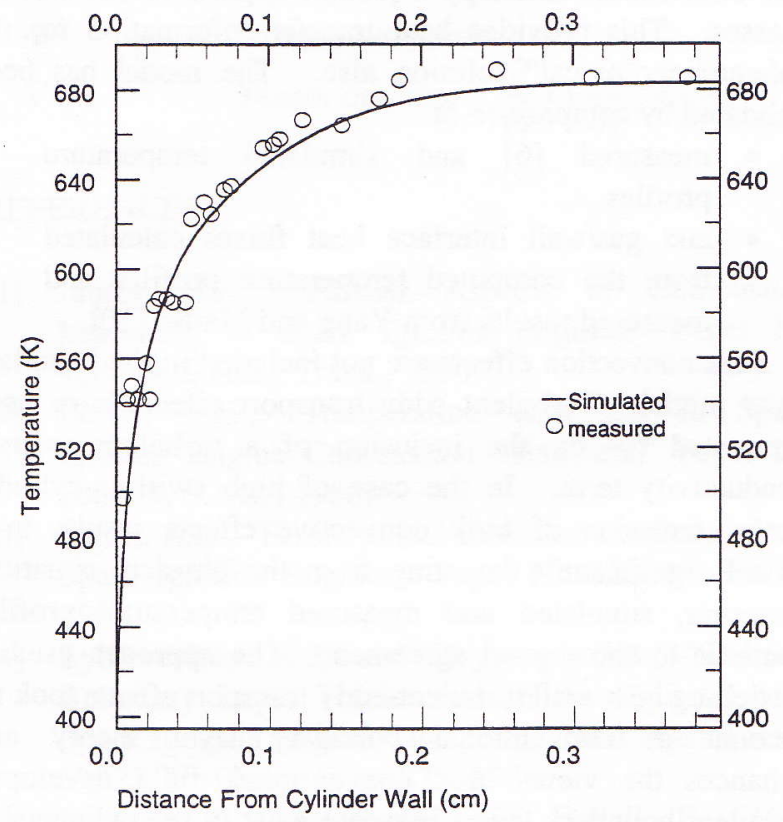

Figure 10. Low Swirl Measured TDC Thermal Boundary Layer Profile (Lucht et al [6]) Compared with Calculated Profile.

the Sandia single cylinder, research engine under "motored" conditions. This engine was fitted with a special toroidal cylinder head to cater for very close optical access enabling reliable and accurate temperature measurements to be achieved extremely close to the wall surfaces. The thermal boundary layer temperature distributions obtained at top dead centre are shown in Figures 9 and 10 for high and low swirl conditions respectively. Also shown are the corresponding thermal boundary layers achieved from the application of the "phenomenological" computer model. The relevant engine operating conditions are listed in Table 1.

In both the high and low swirl cases, good agreement is found between the calculated and measured temperature profiles. Table 2 lists the empirical constants and boundary layer model parameters used to produce the calculated temperature profiles presented in Figures 9 and 10. Values for the core turbulent eddy transport ratio, $C$, vary significantly between the high and low swirl cases. The value for $C$ used in the high swirl case reflects the physical situation where convective effects are overwhelmingly dominant as is the case when in-cylinder fluid motion is high. This constant controls the simulated core gas temperature. The values presented in Table 2 were arrived at by matching the respective simulated and measured core gas temperatures. Values for the thickness of the zone, $\delta$, in which near-wall turbulence effects are assumed to influence thermal conductivity were obtained from consideration of the need to accurately match the computed with the measured temperature profiles.

Initially, due to increased velocity boundary layer thicknesses when in-cylinder charge motion is low (Figure
Table 3. Engine Operating Conditions (Yang \& Martin [10])

$\begin{array}{lc}\text { Compression ratio } & 11.0 \\ \text { Engine speed (r.p.m.) } & 603 \\ \text { Intake air temperature (K) } & 297.4 \\ \text { Intake air pressure }(\mathrm{kPa}) & 137.8\end{array}$

3), larger values were used for $\delta$ in the low swirl case. However, in order to achieve accurate matching of the low swirl measured and calculated temperature profiles, it was necessary to use a value for $\delta$ of approximately half that used in the high swirl case. This is thought to be attributed to the varying nature of the interactions between bulk turbulence and the cylinder wall in the high and low swirl cases [19]. As long as they remained within reasonable limits, the value chosen for the laminar sub-layer thickness had little effect on the calculated temperature profiles. It was necessary to add an extra empirical constant to achieve accurate boundary layer profile simulation in the high swirl case. The constant allows for the influence of turbulence effects within the laminar sub-layer and its effect on the $k_{t} / k$ ratio vis-à-vis the low swirl case is shown in Figure 8. Its usage is justified on the basis that for highly turbulent conditions there is speculation that turbulent eddies could penetrate all the way to the cylinder walls [19]. Adjusting the empirical constant accounting for turbulence effects penetrating the laminar sub-layer alters the gradient of the simulated temperature profile curves adjacent to the cylinder wall.

The thermal boundary layer sub-model is invoked at inlet valve closure where it is assumed that the thermal boundary layer begins to form. This has proven to be successful for both high and low swirl cases. A parametric study investigating the influence of boundary layer development early in the compression stroke has concluded that, within

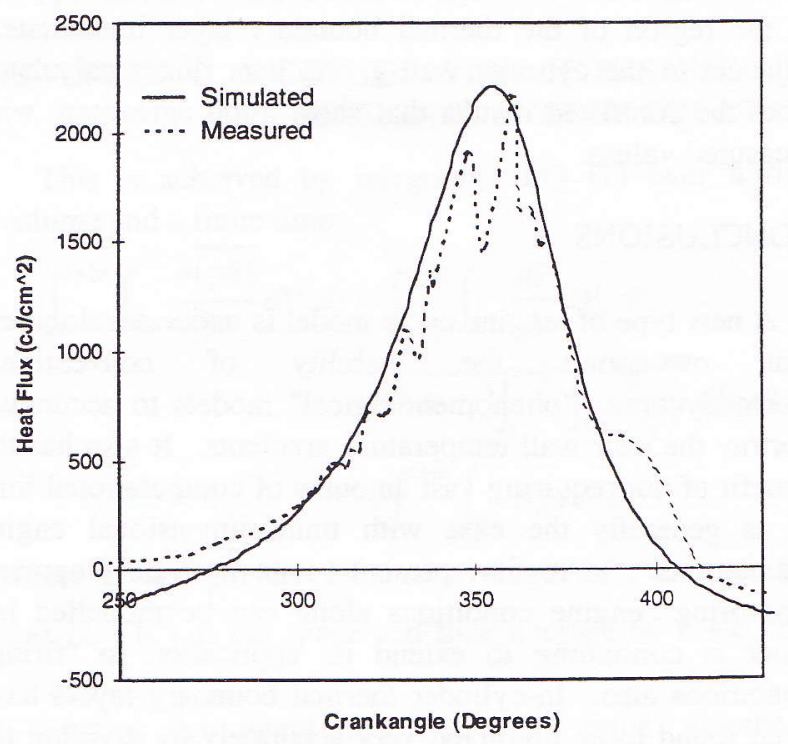

Figure 11. Computed and Measured [10] Cylinder Head Heat Fluxes. 
reasonable limits, the time at which the boundary layer is assumed to commence growth has little effect on the near wall temperature distributions towards T.D.C..

Forty elements were used in each of the three zones in all the simulations detailed in this work. The node spacing was weighted towards the wall boundary which enabled there to be four nodes in the laminar sub-layer. It was found that this level of grid resolution provides stable, accurate solutions with process times of the order of 5 to 15 minutes when executed on a medium sized mainframe computer.

Fourier's Law (EQ 2) has been applied to the near wall region of the simulated temperature profiles to predict cylinder head heat fluxes. In the absence of comprehensive, synchronised thermal boundary layer temperature profiles and corresponding cylinder gas/wall interface heat flux measurements, a second simulation was carried out to model the heat flux measurements made by Yang \& Martin [10] in a modified Fairbanks-Morse diesel engine with a pancake-shaped combustion chamber. The relevant operating conditions are listed in Table 3. Predicted heat fluxes show good agreement with measured results (Figure 11). Initially, all elements are at the intake air temperature. The thermal boundary layer quickly develops and stabilises, in this case after about 10 degrees after which the heat flux calculated from the simulated temperature profiles converges towards the measured results. When heat flux is calculated using the method employed here, results are highly dependent on the temperature profile in the simulated laminar sub-layer. The general form of the remainder of the simulated thermal boundary layer has no effect on the calculated cylinder gas/wall interface heat flux.

In summary, the thermal boundary layer sub-model has been used to successfully predict near wall top dead centre temperature profiles in both high and low swirl cases. To further validate the model, Fourier's Law has been applied to the region of the thermal boundary layer immediately adjacent to the cylinder wall giving heat fluxes calculated from the simulated results that show good agreement with measured values.

\section{CONCLUSIONS}

A new type of engine cycle model is under development that overcomes the inability of conventional thermodynamic, "phenomenological" models to accurately portray the near wall temperature gradients. It also has the benefit of not requiring vast amounts of computational time as is generally the case with multi-dimensional engine simulations. At its present state of development, "motoring" engine conditions alone can be modelled but work is continuing to extend its application to "firing" conditions also. In-cylinder thermal boundary layers have been found to be predicted very accurately by dividing the in-cylinder gases into a number of discrete masses which remain "stacked" in layers adjacent to the cylinder wall. Near-wall temperature distributions are predicted using the one-dimensional Enthalpy Equation applied to the discrete masses. This provides heat transfer information for the "phenomenological" solution also. The model has been validated by comparison of

- measured [6] and simulated temperature profiles

- and gas/wall interface heat fluxes calculated from the computed temperature profiles and measured results from Yang and Martin [10].

Bulk convection effects are not included in the boundary layer model. Turbulent eddy transport effects have been accounted for by the inclusion of a turbulent thermal conductivity term. In the case of high swirl in-cylinder flows, omission of bulk convective effects results in a model significantly deviating from the physical situation. However, simulated and measured temperature profiles continue to show good agreement. The approach used in modelling near-wall turbulent-eddy transport effects took no account of conventional boundary layer theory and enhances the view that conventional, fully developed turbulent boundary layers may not exist in the cylinders of internal combustion engines.

\section{NOMENCLATURE}

$\begin{array}{ll}C & k_{t} / k \\ C_{P} & \text { Specific heat at constant pressure } \\ h & \text { Specific enthalpy } \\ i & \text { Specific internal energy } \\ k & \text { Thermal conductivity } \\ k_{t} & \text { Turbulent eddy thermal conductivity } \\ k_{0} & \text { Initial in-cylinder gas thermal } \\ & \text { conductivity } \\ m & \text { Mass } \\ n & \text { Polytropic exponent } \\ P & \text { Pressure } \\ P_{0} & \text { Initial Pressure } \\ q & \text { Heat flux } \\ r / R & \text { Radial position } \\ S_{h} & \text { Enthalpy sources } \\ S_{i} & \text { Internal energy sources } \\ t & \text { Time } \\ T & \text { Temperature } \\ T_{0} & \text { Initial in-cylinder gas temperature } \\ T_{P} & \text { Nodal temperature at end of time step } \\ T_{P_{0}} & \text { Initial nodal temperature } \\ u & \text { Velocity component in } x \text { direction } \\ u^{\prime} & \text { Fluctuating velocity component in } x \text { dirn. } \\ \mathbf{u} & \text { Mean velocity } \\ v & \text { Specific volume } \\ V & \text { Volume } \\ x & \text { Distance from cylinder wall } \\ \gamma & \text { Fluctuating component of enthalpy } \\ & \end{array}$




\section{REFERENCES.}

[1] James, E.H., "Further Aspects of Combustion Modelling in Spark Ignition Engines," Paper No 900684, S.A.E., Trans., 1990.

[2] James, E.H., "Temperature Gradients in Spark Ignition Engine Combustion Chambers," Paper No 800458, S.A.E., 1980.

[3] James, E.H., "Errors in NO Emission Prediction from Spark Ignition Engines," Paper No 820046, S.A.E., 1982.

[4] Lydford-Pike, E.J. and Heywood, J.B., "Thermal Boundary Layer Thicknesses in the Cylinder of a Spark Ignition Engine," Int. Journ. Heat Mass Trans., Vol27, No10, pp1873-1878, 1984.

[5] Yamada, S., Paulsen, H. and Farrell, P., "Heat Transfer Measurements in a Motored Engine," Paper No 890319, S.A.E., 1989.

[6] Lucht, R.P., Dunn-Rankin, D., Walter, T,. Dreier, T and. Bopp, S. C, "Heat Transfer in Engines: Comparison of CARS Thermal Boundary Layer and Heat Flux Measurements," Paper No 910722, SAE, 1991.

[7] Jennings, M.J. and Morel, T., "An Improved Near Wall Heat Transfer Model for Multi-Dimensional Engine Flow Calculations," Paper No 900251, SAE 1990.

[8] Reitz, R.D., "Assessment of Wall Heat Transfer Models for Premixed-Charge Engine Combustion Computations," Paper No 910267, S.A.E., 1991.

[9] Huh, K.Y., Chang, I. and Martin, J.K., "A Comparison of Boundary Layer Treatments for Heat Transfer in IC Engines," Paper No 900252, S.A.E., 1990.

[10] Yang, J. and Martin, J.K., "Approximate SolutionOne-Dimensional Energy Equation for Transient, Compressible, Low Mach Number Turbulent Boundary Layer Flows," Journal of Heat and Mass Transfer, Vol. 111, pp. 619-624, 1989.

[11] Lavoie, G.A. and Blumberg, P.N., "A Fundamental Model for Predicting Fuel Consumption, NOx and HC Emissions of the Conventional Spark Ignited Engine," Comb. Sci. and Tech., Vol. 21,1980.

[12] Annand, W.J.D., "Heat Transfer in the Cylinders of Reciprocating Internal Combustion Engines," Proc. Instn. Mech. Engrs., Vol.177, No.36, 1963.

[13] Annand, W.J.D. and Ma, T.H., "Instantaneous Heat Transfer Rates to the Cylinder Head Surface of a Small Compression-Ignition Engine," Proc. Instn. Mech. Engrs., Vol.185, No.72/71, 1970.

[14] Lawton, B., "Effect of Compression and Expansion on Instantaneous Heat Transfer in Reciprocating
Internal Combustion Engines," Proc. Instn. Mech. Engrs., Vol.201, No.A3, 1987.

[15] Jennings, M.J. and Morel, T., "Modelling of Turbulent Heat Transfer with Application to IC Engines," Paper No 872104, S.A.E., 1987.

[16] Puzinauskas, P. and Borgnakke, C., "Evaluation of Unsteady Heat Transfer Model for Spark Ignition Engines," Paper No 910298, S.A.E., 1991.

[17] Chen, C. and Veshagh, A., "A One-Dimensional Model for In-Cylinder Heat Convection Based on Boundary Layer Theory," S.A.E. Technical Paper Series, pp.1-17, 1992.

[18] Hall, M.J. and Bracco, F.V., "Cycle Resolved Velocity and Turbulence Measurements Near the Cylinder Wall of a Firing S.I. Engine," Paper No 861530, S.A.E., 1986.

[19] Foster, D.E. and Witze, P.O., "Velocity Measurements in the Wall Boundary Layer of a Spark Ignited Research Engine," Paper No 872105, S.A.E., 1987.

[20] Pierce, P.H., Ghandhi, J.B.and Martin, J.K., "NearWall Velocity Characteristics in Valved and Ported Motored Engines," Paper No 920152, S.A.E., 1992.

[21] Yang, J., Pierce, P., Martin, J.K. and Foster, D.E., "Heat Transfer Predictions and Experiments in a Motored Engine," Paper No 881314, S.A.E., 1988.

[22] Greif, R., Namba, T. and Nikanjam, M., "Heat Transfer During Piston Compression Including Side Wall Effects," Int. J. Heat Mass Transfer, Vol. 22, pp. 901-907, 1979.

[23] Hinze, J.O., Turbulence, McGraw-Hill, New York, 1959.

[24] Patankar, S.V., Numerical Heat Transfer and Fluid Flow, Hemisphere Publishing Corp., 1980.

[25] Schlichting, H., Boundary Layer Theory, McGrawHill, New York, 1960.

\section{APPENDIX A: DISCRETISATION OF THE ONE- DIMENSIONAL ENERGY EQUATION.}

This is achieved by integrating EQ (7) over a finite volume and a finite time:

$$
\begin{aligned}
\int_{t}^{t+\delta t} \int_{\nabla V} \frac{\partial \overline{(\mathrm{\rho} h)}}{\partial t} d V \cdot d t & =\int_{t}^{t+\delta t} \int_{\nabla V} \frac{d \mathrm{P}}{d t} d V \cdot d t \\
& +\overline{\left(k+k_{t}\right)} \int_{t}^{t+\delta t} \int_{\nabla V} \frac{\partial^{2} \overline{\mathrm{T}}}{\partial x^{2}} d V \cdot d t \\
& +\int_{t}^{t+\delta t} \int_{\nabla V} \mathrm{~S}_{h} d V \cdot d t
\end{aligned}
$$

where $\bar{T}$ and $\overline{\rho h}$ are the time averages of $T$ and $\rho h$ [23] and $\overline{\left(k+k_{t}\right)}$ is the space and time average of $k+k_{t}$ over $d V$ and $d t$.

Firstly, the integration over the finite volume is performed using Gauss' Theorem to express the volume derivatives in terms of surface derivatives: 


$$
\begin{aligned}
\int_{t}^{t+\delta t} \frac{\partial \overline{(\mathrm{\rho} h)}}{\partial t} \Delta V d t & =\int_{t}^{t+\delta t} \frac{d \mathrm{P}}{d t} \Delta V d t \\
& +\overline{\left(k+k_{t}\right)} \int_{E} \int_{t}^{t+\delta t}\left(\frac{\partial \overline{\mathrm{T}}}{\partial x}\right)_{E} A_{E} d t \\
& -\overline{\left(k+k_{t}\right)_{W}} \int_{t}^{t+\delta t}\left(\frac{\partial \overline{\mathrm{T}}}{\partial x}\right)_{W} A_{W} d t+\int_{t}^{t+\delta t} \mathrm{~S}_{h} \Delta V d t
\end{aligned}
$$

After integration over a finite time, the above equation becomes:

$$
\begin{aligned}
\partial \overline{(\rho h)} \Delta V & =\partial \mathrm{P} \Delta V+\overline{\left(k+k_{t}\right)} A_{E} A_{E}\left(\frac{\partial \bar{T}}{\partial x}\right)_{E} \delta t \\
& -\overline{\left(k+k_{t}\right)_{W}} A_{W}\left(\frac{\partial \bar{T}}{\partial x}\right)_{W} \delta t+S_{h} \Delta V \delta t
\end{aligned}
$$

where subscripts $E$ and $W$ refer respectively to the east and west faces of the control volume.

If we assume that $\frac{\partial \bar{\rho}}{\partial t} \approx 0$ over a very small time step and that $\frac{\partial \bar{h}}{\partial t}=\bar{C}_{p} \frac{\Delta \overline{\mathrm{T}}}{\Delta \mathrm{t}}$, after dividing by $\delta t, \mathrm{EQ}$ becomes:

$$
\begin{aligned}
\overline{\rho C_{p}} \frac{\Delta \bar{T}}{\delta t} \Delta V & =\frac{\Delta \mathrm{P}}{\delta \mathrm{t}} \Delta V+A_{E}{\overline{\left(k+k_{t}\right)}}_{E}\left(\frac{\partial \bar{T}}{\partial x}\right)_{E} \\
& -A_{W}{\overline{\left(k+k_{t}\right)}}_{W}\left(\frac{\partial \bar{T}}{\partial x}\right)_{W}+\mathrm{S}_{h} \Delta V
\end{aligned}
$$

EQ (A2) is then discretised and formulated to enable a fully implicit, finite volume solution noting that only the time averaged steady temperatures are used as nodal values:

$$
\begin{aligned}
\overline{\rho C_{p}} \frac{\Delta V}{\Delta t}\left(T_{p}-T_{p O}\right) & =\frac{\left(\mathrm{P}-\mathrm{P}_{\mathrm{O}}\right)}{\Delta \mathrm{t}} \Delta V \\
& +A_{E} \overline{\left(k+k_{t}\right)} \frac{T_{E}-T_{P}}{\delta x_{E P}} \\
& -A_{W} \overline{\left(k+k_{t}\right)} \frac{T_{P}-T_{W}}{\delta x_{P W}} \\
& +\mathrm{S}_{h} \Delta V
\end{aligned}
$$

In the situation where $A_{E}=A_{W}=A$, we can divide $\mathrm{EQ}$ (A3) by $A$ to yield:

$$
\begin{aligned}
\overline{\rho C_{p}} \frac{\Delta x}{\Delta t}\left(T_{p}-T_{p O}\right)= & \frac{\left(\mathrm{P}-\mathrm{P}_{\mathrm{O}}\right)}{\Delta \mathrm{t}} \Delta x \\
& \left.+\overline{\left(k+k_{t}\right)}\right)_{E} \frac{T_{E}-T_{P}}{\delta x_{E P}} \\
& \left.-\overline{\left(k+k_{t}\right)}\right)_{W} \frac{T_{P}-T_{W}}{\delta x_{P W}}+\mathrm{S}_{h} \Delta x
\end{aligned}
$$

\section{APPENDIX B: CALCULATION OF THE NET HEAT TRANSFER FROM EACH DISCRETE MASS.}

The specific energy change of each finite volume due to heat transfer can be calculated once the discretised EQ (A4) has been solved to give the new temperatures. If $\mathrm{EQ}$ ( $\mathrm{A} 1$ ) is rearranged and the conduction terms are replaced by $\mathrm{Q}$, we get:

$$
Q=\partial(\rho h) \Delta V-d P \Delta V-S_{h} \Delta V \Delta t
$$

or, in specific terms for the Control Volume (CV):

$$
Q_{C V}^{\prime \prime \prime}=\partial(\rho h)_{C V}-d \mathrm{P}-\mathrm{S}_{h C V} \Delta t
$$

We have assumed that the energy change due to conduction in each discrete mass element is approximately equal to the energy change due to conduction in the corresponding control volume i.e. $Q_{\text {mass }} \approx Q_{C V}$. Since $Q_{C V}=Q_{C V}^{\prime \prime \prime} \times \bar{V}_{C V}$, we get

$$
q_{\text {mass }} \times m_{\text {mass }} \approx Q_{C V}^{\prime \prime \prime} \times \bar{V}_{C V}
$$

which, noting that $V_{C V}=\bar{v}_{C V} \bar{m}_{C V}$, can be rearranged to give:

$$
q_{\text {mass }} \approx Q_{C V}^{\prime \prime \prime} \times \frac{\bar{v}_{C V} \bar{m}_{C V}}{m_{\text {mass }}}
$$

According to our previous assumptions, for a small increment in time $\bar{m}_{C V} \approx m_{\text {mass }}$ and so

$$
q_{\text {mass }} \approx Q_{C V}^{\prime \prime \prime} \bar{v}_{C V}
$$

Substitution of EQ (B1) into (B2) yields :

$$
q_{\text {mass }} \approx\left(\partial(\rho h)_{C V}-d \mathrm{P}-\mathrm{S}_{h_{C V}} \Delta t\right) \bar{v}_{C V}
$$

Noting that $\partial(\rho h)_{C V} \cong\left[\bar{\rho} \bar{C}_{p}\left(T_{p}-T_{p O}\right)\right]_{C V} \quad$ and $\bar{\rho}_{C V} \bar{v}_{C V}=1, q_{\text {mass }}$ can be expressed in a form which can be used for each discrete mass within the "phenomenological" model:

$$
q_{\text {mass }} \approx\left[\bar{C}_{p}\left(T_{p}-T_{p O}\right)\right]_{C V}-\left(\mathrm{P}-\mathrm{P}_{O}\right) \bar{v}_{C V}-\mathrm{S}_{h} \Delta t \bar{v}_{C V}
$$

where $C V$ relates to the control volume approximating each discrete mass. 
APPENDIX C: SIMULTANEOUS EQUATIONS TO BE SOLVED BY ITERATION PROCEDURE.

The matrix form of the simultaneous equations to be solved by iteration in order to attain the thermal boundary layer temperature variation along with the adiabatic core temperature is given below:

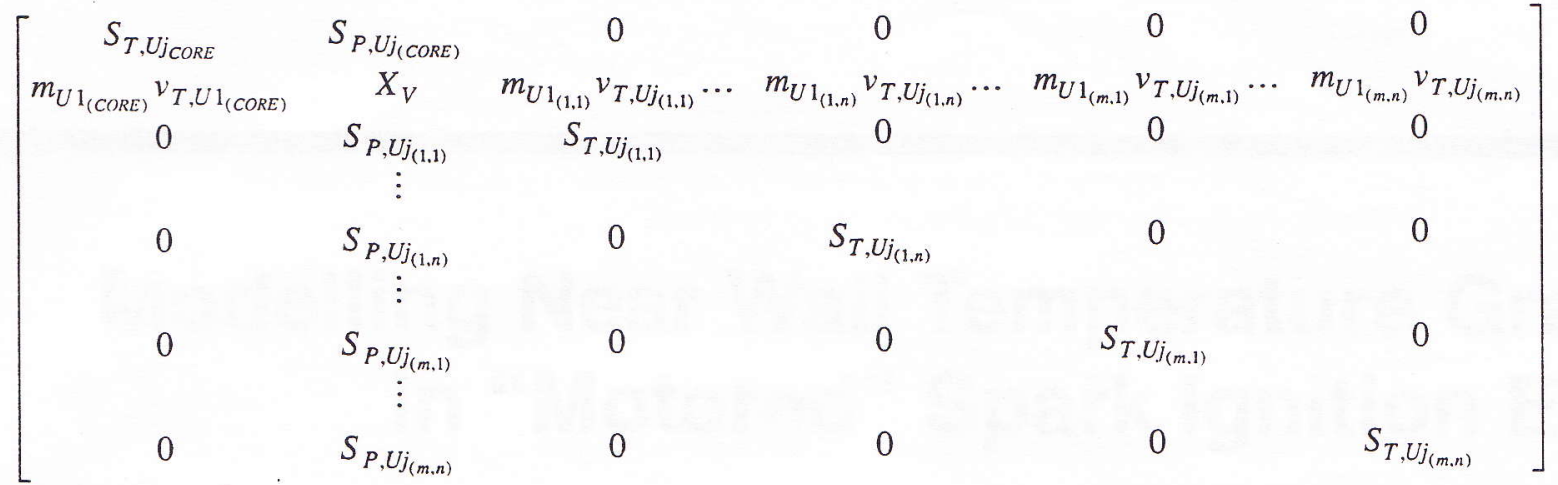

$$
\begin{aligned}
& {\left[\begin{array}{c}
\Delta T_{U_{(C O R E)}} \\
\Delta P \\
\Delta T_{U_{(1,1)}} \\
\vdots \\
\Delta T_{U_{(1, n)}} \\
\vdots \\
\Delta T_{U_{(m, 1)}} \\
\vdots \\
\Delta T_{U_{(m, n)}}
\end{array}\right]=\left[\begin{array}{c}
\Delta S_{U(C O R E)} \\
\sum_{0}-\sum_{k=1, m} m_{U 1_{(k, l)}} v_{U j_{(k, l)}}+m_{U 1_{(C O R E)}} v_{U j_{(C O R E)}} \\
\Delta S_{U(1,1)} \\
\vdots \\
\Delta S_{U(1, n)} \\
\vdots \\
\Delta S_{U(m, 1)} \\
\vdots \\
\Delta S_{U(m, n)}
\end{array}\right]}
\end{aligned}
$$

The order of the matrix equates to the number of individual mass elements under consideration in the unburned charge of the "motored" engine. In the above matrix:

$$
\begin{aligned}
& X_{V}=\sum_{k=1, m} \sum_{l=1, n} m_{U 1_{(k . l)}} v_{P, U j_{(k, l)}}+m_{U 1_{1} \text { CORE) }} v_{P, U j_{(C O R E)}} \\
& \Delta S_{U_{(C O R E)}}=\left\{s_{U 0_{(C O R E)}}-s_{U j_{(C O R E)}}+\frac{2 \Delta Q_{(C O R E)}}{m_{U 1_{(C O R E)}}\left(T_{U 0_{(C O R E)}}+T_{U_{(C O R E)}}\right)}\right\} \\
& \Delta S_{U_{(i, j)}}=\left\{s_{U 0_{(i, j)}}-s_{U j_{(i, j)}}+\frac{2 \Delta Q_{(i, j)}}{m_{U 1_{(i, j)}}\left(T_{U 0_{(i, j)}}+T_{U j_{(i, j)}}\right)}\right\} \text { where } k=1, m \text { and } l=1, n .
\end{aligned}
$$

$\underline{\text { Symbols }}$
$S \quad$ Entropy
$S_{T} \quad \frac{d S}{d T}$
$S_{P} \quad \frac{d S}{d P}$
$U_{0}$
Sub Sub-script
$v_{T} \quad \frac{d v}{d T}$
$v_{P} \quad \frac{d v}{d P}$
$k$
Unburnt charge state at beginning of each compression step
Sub-scripts

$\begin{array}{ll}U_{j} & \begin{array}{l}\text { Unburnt charge } j^{\text {th }} \text { estimate in iteration } \\ \text { procedure }\end{array} \\ U_{I} & \begin{array}{l}\text { Unburnt charge state at end of each } \\ \text { compression step }\end{array}\end{array}$

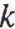
$l$
$m \quad$ Total number of zones $(=3)$
$n$
CORE
Boundary layer zone number:

$$
\begin{array}{ll}
1- & \text { Cylinder head } \\
2- & \text { Cylinder wall } \\
\text { 3- } & \text { Piston crown }
\end{array}
$$
Element number
Number of boundary layer mass elements in each zone.
Refers to the adiabatic core 